\title{
B2B SOCIAL MEDIA MARKETING MIX OPTIMIZATION MODEL: A CASE STUDY OF A SME IN CORPORATE TRAINING SERVICES
}

\author{
Devi Prasad Ghosh ${ }^{1 *}$ \\ ${ }^{*}$ Head of Marketing Department, Institute of Management Technology (IMT), Hyderabad. \\ Director, GraphMatrix Solutions, Hyderabad
}

\section{*Corresponding Author: -}

\begin{abstract}
: -
The paper conceptualized a B2B Social Media Marketing Optimization Model by using Linear Programming mathematical technique. Social Media Marketing as part of digital marketing mix is seen as an effective one-to-one communication and an interactive media. But Social Media Marketing channels suffers from its poor reach compared to other digital media. As a practice, social media marketing is chosen as per ease of operation, lower cost and not on any quantitative measurements. The optimization model is first of its type since it uses media effectiveness (reach), media efficiency (Cost) and media quality (engagement) as the basis for building the optimization model. The concept presented takes into account complete cost of social media marketing that includes operations cost, production cost and design cost. The other model limits cost of Social Media Marketing to media cost only and usually account for production cost and design cost as a common marketing support cost, which in social media cases may consume a large portion of resources and cost. This also create problems to ascertain the cost in case of owned media or earned media where paid media cost is zero. The model also presents a case that if Social Media Marketing Mix is chosen on basis of mathematical calculation, the outcome can be enhanced.

This case will be best suited to marketer and agency professionals who are involved in allocation of limited budget, materials, systems and people resources as the situation present in the case is almost similar to one faced by many other companies. Management students could get an insight as to how dynamic is the real-life situation and how companies would need to be alert to changing assumptions and constraints. The decision case presented here will specifically help in assimilating:

1. What a Linear Programming Optimization Model can be applied to real life decision situations in social media and how alternative decision can be mathematically evaluated.

2. How a company can enhance its Social Media Marketing efficiency and effectiveness by improving upon constraints through qualitative changes.

3. How Social Media Marketing Mix decisions should be evaluated on both quantitative and qualitative parameters, and under different market conditions and company constraints.
\end{abstract}

Keywords: - Digital Marketing Strategy, Social Media Marketing Mix, Optimization Model, Linear Programming Model, Customer-Brand Engagement.

\section{(우 $\circledast$ (1)}




\section{Background}

Social Media decisions, unlike other traditional media approach, are metrics based that are evaluated for outcomes before it is implemented. The primary objective and therefore the primary metrics for a Social Media Marketing Mix is to increase customer reach. The concept is explained by consumer response model AIDA (Awareness, Interest, Desire and Action). The metrics stated here is Ad Effectiveness measure of a social media. The second metrics is to achieve cost efficiencies in budget allocations to each media under given resource and market constraints. Third important metrics is to measure media impact quality of any Social Media vehicle in terms of audience engagement. An optimized social media marketing mix is achieved through consideration of these three metrics of Media Effectiveness, Media Efficiency and Media Impact Quality.

As we increase the budgets for any media on each of the social media channels of Social Community, Social Publishing, Social Commerce and Social Entertainment, the customer reach in numbers increases in proportion. The paper presents a case of a SME developing an optimization model for developing a social media marketing strategy for promotion of its training services using popular social media marketing mix - Brand Community (Social Relationship), Facebook (Social Publishing), You Tube (Social Entertainment) and Discussion Forum (Social Commerce)

\section{The Company}

GraphMatrix Solutions is a Start-Up in IT/Digital Training and Consulting services with its head office in Hyderabad. Company is involved in imparting Certification Training services to Professionals, Advertising Agencies, Consulting Firms, Online Publishers, SMEs, Corporates and Educational Institutions for domains Digital Marketing and Project Management as in-company location-based model as well as off-location outsourcing model. The company is currently focused on developing proprietary models on which company intends to position itself and differentiate from other companies offering similar services.

\section{Social Media Marketing Mix Optimization}

The problem data was obtained through Depth Interview qualitative research tool of company management team. For each media option the budget for these operations is shown below (in Rs per unit) in Table 1. One unit of digital media product is defined as engagement per 1000 Customer reach Therefore, the Media Operations Cost, Production Cost, Design Cost, Total Media Cost and Customer Engagement are all calculated on per unit basis i.e. per 1000 customer reach.

Table 1: Social Media Marketing Vehicle Costs and Outcome Customer Engagement

\begin{tabular}{|c|c|c|c|c|c|}
\hline Social Media Channel Mix & $\begin{array}{c}\text { Media } \\
\text { Operations } \\
\text { Cost } \\
\text { (in Rs.) }\end{array}$ & $\begin{array}{c}\text { Production } \\
\text { Cost } \\
\text { (in Rs.) }\end{array}$ & $\begin{array}{l}\text { Design } \\
\text { Cost (in } \\
\text { Rs.) }\end{array}$ & $\begin{array}{l}\text { Total Media } \\
\text { Cost (in Rs.) }\end{array}$ & $\begin{array}{c}\text { Customer } \\
\text { Engagement } \\
\text { (Nos) }\end{array}$ \\
\hline 1. Discussion Forum & 2 & 3 & 2 & 7 & 15 \\
\hline 2. You Tube & 4 & 2 & 3 & 9 & 25 \\
\hline 3. Facebook & 3 & 3 & 4 & 10 & 30 \\
\hline 4. Brand Community & 7 & 4 & 5 & 16 & 45 \\
\hline
\end{tabular}

Given the current state of the digital marketing budget situation in the company, the company management decided that, for each year, for total allowable Digital Marketing budget of Rs. 210000, they will have Rs.100000 as Media Operations Budget, Rs.50000 of Production budget and Rs.60000 of Design budget. Company wanted to estimate how much of each of the budget company needs to spend per year so as to maximize the yearly customer response.

The company management also had a second situation to decide how much budget to devote to each of the three operations (Designing, Production and Media Operations) by changing the composition of the work force by additional training, within the total allowable budget amount of Rs.210000 (= Rs.100000 + Rs.50000 + Rs.60000). Company also wanted to estimate how much of each direct marketing vehicle the company needs to spend per year in this case so as to maximize the yearly customer response.

The first step, in order to arrive at the best possible solution the company decided to formulate the problem into a linear programming model of the digital marketing operations variables and constraints for both the situations.

In formulating the mathematical programming model company had to establish the variables, constraints and parameters on which the model will be based. The variables include the decision variables and output variables.

The variables are:

$\mathrm{X}_{\mathrm{i}}$ be the number of units of Digital Media vehicles $\mathrm{i}(\mathrm{i}=1,2,3,4)$ made per year

$\mathrm{Mm}$ be the number of Digital Media Budget spent in Media Operation per year

$\mathrm{Mp}$ be the number of Digital Media Budget spent in Production per year

$\mathrm{M}_{\mathrm{d}}$ be the number of Digital Media Budget spent in Designing per year 
Where, $\mathrm{X}_{\mathrm{i}}>=0 \mathrm{i}=1,2,3,4$ and $\mathrm{Mm}, \mathrm{Mp}, \mathrm{Md}_{\mathrm{d}}>=0$

\section{The constraints are:}

(a) Social Media Marketing Budget definition

$\mathrm{M}_{\mathrm{m}}=2 \mathrm{X}_{1}+4 \mathrm{X}_{2}+3 \mathrm{X}_{3}+7 \mathrm{X}_{4}$ (Media Operations)

$\mathrm{Mp}=3 \mathrm{X} 1+2 \mathrm{X} 2+3 \mathrm{X} 3+4 \mathrm{X} 4$ (Production)

$M_{d}=2 X_{1}+3 X_{2}+2 X_{3}+5 X_{4}$ (Design)

(b) Social Media Marketing Budget limits

The Social Media Marketing budget limits depend upon the situation being considered. In the first situation, where the maximum budget that can be spent on each operation is specified, we simply have:

$\mathrm{M}_{\mathrm{m}}<=100000$ (Media Operations)

$\mathrm{Mp}<=50000$ (Production)

$\mathrm{Md}<=60000$ (Design)

In the second situation, where the only limitation is on the total budget spent on all operations, we simply have: $\mathrm{Mm}+\mathrm{Mp}+\mathrm{Md}<=210000$ (Total Social Media Marketing Budget)

\section{The Objective function is:}

Maximizes Customer Engagement, E

Hence, Engagement, $\mathrm{E}=15 \mathrm{X} 1+25 \mathrm{X}_{2}+30 \mathrm{X} 3+45 \mathrm{X} 4$ Which gives us the complete formulation of the problem.

The solution to this function was calculated using Linear Programming Tool LINDO software. The optimal solution to the LP for the first situation has value as follows:

$$
\begin{aligned}
& E=5,80,000 \text { and that } M_{m}=82000, M_{p}=50000, M_{d}=60000, X_{1}=0, X_{2}=16000, X_{3}=6000 \text { and } \\
& X_{4}=0 \text {. That is } E=5.8 \text { lacs responses, } X_{1}=0, X_{2}=16000, X_{3}=6000 \text { reach and } X_{4}=0 .
\end{aligned}
$$

The solution presented interesting direction to the company, not to spend any budget on Social Media Marketing Vehicle 1 and SMM Vehicle 4. The company management was totally surprised with the findings and needed to explain the following?

- How can you explain the fact that it appears that the best thing to do is not to spend any budget on the Social Media vehicle 1 with the lowest Vehicle Cost per unit reach?

- How can you explain the fact that it appears that the best thing to do is not to spend any budget on the Social Media vehicle 4 with the highest Customer Engagement per unit reach?

Referring back to the present situation company management came up with one observation. We see that at the LP optimal we have Rs. 18,000 of Social Media Marketing budget that is not used ( $\mathrm{Mm}=\mathrm{Rs} .82000$ compared with a maximum Social Media Marketing budget of Rs.100000) but all of the production and design budget is used.

For each constraint in the LP problem one can have a "Slack or Surplus" situation. This tells us that, for a particular constraint, the difference between the left-hand side of the constraint when evaluated at the LP optimal (i.e. when evaluated with $\mathrm{X}_{1}, \mathrm{X}_{2}, \mathrm{X}_{3}$ and $\mathrm{X}_{4}$ taking the values given above) and the right-hand side of the constraint.

Constraints with a "Slack or Surplus" value of zero are said to be tight or binding in that they are satisfied with equality at the LP optimal. Constraints that are not tight are called loose.

After this understanding of the problem, the company decided to formulate an LP for the second situation with only limitation for the total social media marketing budget spent on all operations in a year.

The solution to this situation was also obtained using mathematical software LINDO for LP.

The optimal solution to the LP for second situation has value $E=787500$ ( 7.87 lacs) and that

$$
\mathrm{Mm}_{\mathrm{m}}=78750, \mathrm{Mp}=78750, \mathrm{Md}=52500, \mathrm{X} 1=0, \mathrm{X}_{2}=0, \mathrm{X} 3=26250 \text { and } \mathrm{X} 4=0 \text {. }
$$

This implies that company only use Social Media vehicle 3.

Management here noted that the associated customer response is higher than before $(7,87,500$ compared with 5,80,000, an increase of $36 \%$ ). This indicates that the budget allocation given in situation one of Rs.100,000, Rs.50,000 and Rs.60,000 for Media Operations, Production and Designing respectively by the company management was not an appropriate decision!

\section{Social Media Marketing Mix Evaluation}

After seeing the improvement in the turnover of the company on changing the constraint, the company management wanted to know as to how the solution changes as the constants such as media budget, production budget and designing budget changes. Management found that it was necessary to be absolutely sure of their social media marketing strategy before implementation. The following three issues was identified by management team as important for evaluating the social media marketing strategy:

- Robustness; 
- Planning Optimality; and

- Sensitivity Analysis

\section{Robustness}

Since the cost data is not completely accurate as it is based on an estimated value from many observations and so management would like some confidence that their proposed course of action is relatively insensitive (robust) with respect to data inaccuracies. For example, management considered that the designing budget consumed by vehicle 3 is not accurate. It is currently set to exactly Rs.2.0. But in reality, it is likely to change as Rs, 2.10 or Rs.1.90. What is the likely effect of this on the decision?

What company management was interested here to know is "the outcome of the strategy" rather than the specific numeric values. The response number of 5,80,000 gave the outcome of the strategy as "none of social media vehicle 1 or 4 , lots of social media vehicle 2 and a reasonable amount of social media vehicle 3". The response number of $7,87,500$ gave the outcome of the strategy as "only of social media vehicle 3". What management wanted to know was when the designing budget of Rs.2 for vehicle 3, is replaced by Rs. 2.10 or Rs.1.90, the general outcome of strategy remains the same or it changes, as was the case with change in operations budget constraints. If the general outcome of the strategy remains essentially the same under small data changes, we say that the strategy is robust.

\section{Planning Optimality}

With regard to planning, management is interested in seeing how the total consumer engagement changes as the constant data changes. For example, for the social media mix planning how would improving the output customer engagement per unit on social media vehicle 4 (e.g. by $10 \%$ to 495 by raising the media impact) influence upon the optimal strategy.

\section{Sensitivity Analysis}

The company management decided upon to perform sensitivity analysis to evaluate various decision alternatives. Company first decided to deal with each of constants and constraints in turn, that is noted the figures obtained for a single change. The case of two or more things change at the same time was avoided in this study, as it will effectively need to resolve the LP Problem again.

The management decided to do the following sensitivity analysis as they concluded that analysis of no other constants and constraints are needed to draw conclusions.

(a) Changing the objective function coefficient (Customer Response) for a variable:

Company decided to vary the coefficient of $\mathrm{X}_{2}$ in the objective function. How will the LP optimal solution change? Currently $X_{1}=0, X_{2}=16000, X_{3}=6000$ and $X_{4}=0$. The sensitivity analysis tells us that, provided the coefficient of $X_{2}$ in the objective function lies between 235.71 and 450, the values of the variables in the optimal LP solution will remain unchanged, though the actual optimal solution value will change.

In terms of the original problem, we are effectively saying that the decision to use 16000 of vehicle 2 and 6000 of vehicle 3 remains optimal even if the responses per unit on vehicle 2 is not actually 250 (but lies in the range 235.71 to 450).

In terms of the interpreting simplex algorithm this arises because the current simplex basic solution (vertex of the feasible region) remains optimal provided the coefficient of X2 in the objective function lies between 235.71 and 450 .

\section{(b) Forcing a variable which is currently zero to be non-zero}

For the variables, the Reduced Cost gave the management, for each variable, which is currently zero (X1 and X4), an estimate of how much the objective function will change if they make that variable non-zero.

Hence, they have the data as:

\begin{tabular}{lcll} 
Variable & $\mathrm{X}_{1}$ & $\mathrm{X}_{4}$ \\
Opportunity/Reduced Cost & 1.5 & 0.2 \\
New value $(=$ or $>=)$ & $\mathrm{X}_{1}=\mathrm{A}$ & $\mathrm{X}_{4}=\mathrm{B}$ \\
$\qquad$ & $\mathrm{X}_{1}>=\mathrm{A}$ & $\mathrm{X}_{4}>=\mathrm{B}$ \\
\multicolumn{1}{c}{$\begin{array}{ll}\text { Or } \\
\text { Estimated objective function change }\end{array}$} & $1.5 \mathrm{~A}$ & $0.2 \mathrm{~B}$
\end{tabular}

The objective function will always get worse (go down if we have a maximisation problem, go up if we have a minimisation problem) by at least this estimate. The larger A or B are the more inaccurate this estimate is of the exact change that would occur if we were to resolve the LP with the corresponding constraint for the new value of X1 or X4 added. Note here that the value in the "Reduced Cost" column for a variable is often called the "opportunity cost" for the variable. The other alternative interpretation of the reduced cost is the amount by which the objective function coefficient for a variable needs to change before that variable will become non-zero.

Hence for variable $\mathrm{X}_{1}$ the objective function needs to change by 1.5 (increase since company is maximising) before that variable becomes non-zero. In other words, referring back to original situation, the responses per unit on media vehicle 
1 would need to need to increase by 1.5 before it would be profitable to spend any budget on media vehicle 1 . Similarly, the response per unit on media vehicle 4 would need to increase by 0.2 before it would be effective to spend any budget on media vehicle 4 .

(c) Changing the right-hand side of a constraint.

For each constraint the column headed Shadow Price told the company management exactly how much the objective function will change if there is change in the right-hand side of the corresponding constraint within the limits given in the Allowable Min/Max RHS column. The values are presented in Table 2 below:

Table 2: Analysis of Constraints

\begin{tabular}{|c|c|c|c|}
\hline Constraint & Media Operations & Production & Design \\
\hline Opportunity Cost (ignore sign) & 0 & 0.80 & 0.30 \\
\hline Change in right-hand side & $\mathrm{A}$ & $\mathrm{B}$ & $\mathrm{C}$ \\
\hline Objective function change & $0 \mathrm{a}$ & $0.80 \mathrm{~b}$ & $0.30 \mathrm{c}$ \\
\hline Lower limit for right-hand side & 82000 & 40000 & 33333.34 \\
\hline Current value for right-hand side & 100000 & 50000 & 60000 \\
\hline Upper limit for right-hand side & - & 90000 & 75000 \\
\hline
\end{tabular}

For example, for the production budget constraint, provided the right-hand side of that constraint remains between 40000 and 90000 the objective function change will be exactly 0.80 [change in right-hand side from 50000].

The direction of the change in the objective function (up or down) depends upon the direction of the change in the righthand side of the constraint and the nature of the objective (maximise or minimise).

To decide whether the objective function will go up or down the following will give the answer:

(a) Constraint more restrictive after change in right-hand side implies objective function worse and constraint less restrictive after change in right-hand side implies objective function better.

(b) Since objective is maximize customer engagement then worse means down, better means up.

Hence, the value in the column headed Shadow Price for a constraint is often called the "marginal value" or "dual value" for that constraint. It is noted that, as would seem logical, if the constraint is loose the shadow price is zero (as if the constraint is loose a small change in the right-hand side cannot alter the optimal solution).

\section{Managerial Use}

- In fact the approach taken both for robustness and planning issues is identical and interrelated, it is often best to study it together under sensitivity analysis.

- Given the LP package it is a simple matter to change the data and resolve to see how the solution changes (if at all) as certain key data items change before actually implementing the change in real life situation.

- In fact, as a by-product of using the simplex algorithm, we automatically get sensitivity information (e.g. the reduced cost information given on the LP output for the media mix planning problem). Therefore, it is worthwhile to evaluate the decision alternatives.

- For the variables, the Reduced Cost (also known as Opportunity Cost) column gives us, for each variable, which is currently zero, an estimate of how much the objective function will change if we make that variable non-zero. This is often called the "reduced cost" for the variable. This give idea into effectiveness of the media for digital media mix strategy.

- For each constraint the column headed Shadow Price tells us by how much the objective function will change if we change the right-hand side of the corresponding constraint. This is often called the "marginal value" or "dual value" for the constraint. Therefore, managers can concentrate on removing constraints, which will give maximum customer responses.

- This sensitivity information gives manager a measure of how robust the solution is i.e. how sensitive it is to changes in input data that enables manager in scenario building from Optimistic to Pessimistic and, also evaluates the outcome before implementation.

\section{Bibliography}

[1] Anderson D.R., Seweeney D.J. \& Williams T.A. (2001). "Quantitative Methods for Business" $13^{\text {th }}$ Edition, South Western College Publishing, Bangalore (India), pp 216 - 477

[2] Tracy, Tuten \& Michael R Solomon (2013). "Social Media Marketing”, First Edition, Pearson Education, Delhi (India).

[3] Problem Data (March 2019) on Social Media Marketing through Depth Interview with company management of "GraphMatrix Solutions", Hyderabad (India) 